\title{
GAF.Educação: desafios e potencialidades para o desenvolvimento da M-learning
}

\section{GAF.Education: challenges and potential for the development of M-learning}

\author{
Maria Tanise Raphaelli Bosquerolli Antunes \\ Universidad de la Empresa
}

\author{
Anna Helena Silveira Sonego \\ Universidade Federal do Rio Grande do Sul
}

\begin{abstract}
Resumo: Este artigo apresenta-se em uma versão estendida de um trabalho anterior sobre a criação e uso do aplicativo educacional GAF. EDUCAÇÃO. Diante desse contexto, objetiva-se analisar as potencialidades e desafios para utilização do GAF. EDUCAÇÃO, como um objeto de aprendizagem para o desenvolvimento da M-learning em sala de aula. Neste sentido, tem o propósito de contribuir nos processos de autoria e construção de competências tecnológicas com alunos através do uso dos dispositivos móveis (DM). A metodologia utilizada para o seu desenvolvimento envolveu quatro etapas: concepção do projeto; referencial teórico e planejamento; implementação e avaliação, com 20 estudantes do ensino médio. O Objeto de Aprendizagem (OA) apresenta materiais complementares visando introduzir conteúdo de Geografia, Arte e Filosofia através dos DM no contexto escolar. Como resultados, constatou-se que o GAF.Educação pode auxiliar os discentes na pesquisa, comunicação, autoria e na capacitação para utilização de diferentes tecnologias, contribuindo no processo de ensino aprendizagem.
\end{abstract}

Palavras-chave: M-learning, Objeto de aprendizagem, Autoria, Competência tecnológica, GAF.Educação.

\begin{abstract}
This article is presented in an extended version of a previous work on the creation and use of the GAF educational application. EDUCATION. Given this context, the objective is to analyze the potential and challenges for using GAF. EDUCATION, as a learning object for the development of M-learning in the classroom. In this sense, it has the purpose of contributing to the processes of authorship and construction of technological skills with students through the use of mobile devices (DM). The methodology used for its development involved four stages: project design; theoretical framework and planning; implementation and evaluation, with 20 high school students. The Learning Object (OA) presents complementary materials aimed at introducing content from Geography, Art and Philosophy through DM in the school context. As a result, it was found that the GAF. Educação can assist students in research, communication, authorship and training to use different technologies, contributing to the teaching-learning process.
\end{abstract}

Keywords: M-learning, Learning object, Authorship, Technological competence, GAF. Educação. 
ISSN digital 1982-1654

ISSN impresso 1516-084X revista@pgie.ufrgs.br

ANTUNES, Maria Tanise Raphaelli Bosquerolli; SONEGO, Anna Helena Silveira. GAF.Educacão: desafios e potencialidade para o desenvolvimento da M-learning. Informática na Educação: teoria \& prática, Porto Álegre, v. 23, n. 2 p. 142-161 maio./agol. 2020 


\section{Introdução}

O crescente desenvolvimento na área tecnológica e da informática possibilitou uma transformação no cenário social, caracterizado, atualmente, pela hiperconectividade e pela comunicação em rede. Os avanços científicos proporcionaram condições para que os equipamentos tecnológicos se tornem cada vez menores no seu tamanho e acessíveis financeiramente. Com isso, permite que as pessoas e, especialmente, os estudantes tenham acesso a algum tipo de dispositivos móveis (DM), como smartphones e tabletes com internet (3G, 4G ou Wi-fi) disponível no aparelho.

Esse cenário vislumbra uma educação voltada para o desenvolvimento de competências tecnológicas e aponta para a utilização dos dispositivos e de seus recursos com objetivos educacionais, possibilitando o fortalecimento da M-learning. Uma aprendizagem que proporciona novas formas de criar conteúdo, de visualização e comunicação, ampliando as possibilidades no processo de ensino e aprendizagem dos estudantes.

Desse modo, o objetivo deste artigo é analisar as potencialidades e desafios para utilização do GAF. EDUCAÇÃO como um objeto de aprendizagem para o desenvolvimento da M-learning em sala de aula Esse Objeto de Aprendizagem (OA) tem, como propósito, contribuir para amplificar a aprendizagem, desenvolver a autoria e a competência tecnológica com alunos do Ensino Médio.

Assim, o reconhecimento da importância de inserir esses dispositivos de maneira eficaz na prática escolar motivou a realização desta pesquisa, procurando o entendimento sobre como eles, mais especificamente, o uso de um OA na forma de Aplicativo (App) educacional, podem contribuir para a aprendizagem dos alunos de ensino médio. Para tanto, a validação do GAF.Educação deu-se em uma escola da rede pública estadual do município de Barão do Triunfo, RS, com uma turma de $2^{\circ}$ ano do Ensino Médio.

Portanto, este artigo apresenta-se em uma versão estendida de um trabalho anterior sobre a construção e o uso do aplicativo educacional (GAF. EDUCAÇÃO). Sendo assim, destaca-se que o presente estudo está estruturado em cinco seções. A primeira aponta a introdução, com descrição do tema e objetivo de pesquisa. Na segunda, abordam-se os aspectos legais que apontam para o uso das tecnologias digitais (TD) na educação e discorre-se sobre o processo da autoria e da M-learning através de Objetos de Aprendizagem. Ainda nessa seção, apresenta-se uma relação de trabalhos correlatos com o intuito de corroborar com os pressupostos apresentados sobre essa temática. A seção três destina-se à metodologia e aos caminhos percorridos na pesquisa. A quarta refere-se à análise e discussão dos dados coletados. Por último, apresenta-se a seção das considerações finais, as quais indicam as contribuições do objeto de aprendizagem GAF.Educação para a o desenvolvimento da autoria e da aprendizagem dos alunos do ensino médio. 


\section{Tecnologias Digitais na educação: possibilidades e desafios}

O advento da internet e seu potencial econômico, social e educacional apontou a necessidade de inserir as tecnologias no contexto escolar e preparar os jovens aprendizes para atender as necessidades emergentes, tanto do mercado quanto pessoal. Neste sentido, refere-se ao pessoal proporcionar ao educando o contato com recursos tecnológicos, favorecendo sua formação integral e independência digital. Já, na visão de mercado, atribui-se à condição de preparar os jovens para o ingresso no mundo do trabalho, cada vez mais informatizado e com o uso de dispositivos móveis (MORAN, 2012; PERRENOUD 2013).

Nesse contexto, a legislação brasileira vem ao encontro das mudanças sociais e tecnológicas que caracterizaram o final dos anos de 1980, procurando adequar a educação às novas tecnologias, enfatizando a necessidade de preparar os jovens para sua utilização (VALENTE, 2005). Sendo assim, a Lei de Diretrizes e Bases da Educação Nacional - LDBEN (BRASIL, 1996) determina que a educação deve estar vinculada ao mundo do trabalho e à prática social e sua finalidade é o pleno desenvolvimento do educando, seu preparo para o exercício da cidadania e para prosseguir em estudos posteriores. Essa Lei também aborda que, ao final do ensino médio, o educando domine os princípios científicos e tecnológicos que regem a produção moderna e que conheça as diferentes formas de linguagem.

No contexto da atualidade, pode-se concluir que a LDBEN se refere ao uso de dispositivos móveis, à comunicação através da internet, à pesquisa na web e ao domínio das tecnologias digitais (BRASIL, 1996). Além disso, inclui o manuseio dos smartphones e tablets e suas funcionalidades que permitam explorar as ferramentas de vídeo, áudio, imagem, texto entre outras.

Ainda sobre os fins da educação básica, os Parâmetros Curriculares Nacionais para o Ensino Médio (PCNEM) determinam que, ao concluir essa etapa de ensino, o aluno deve ter adquirido os "conhecimentos básicos, a preparação científica e a capacidade de utilizar as diferentes tecnologias relativas às áreas de atuação" (BRASIL, 2000, p. 5). Dessa forma, é imprescindível que o planejamento escolar inclua, em seu currículo, o uso das TD para possibilitar ao educando sua plena formação. Assim sendo, pressupõe-se que, para prosseguir nos estudos, ingressar no mundo do trabalho e para ter pleno exercício da cidadania, faz-se necessário desenvolver competências relacionadas ao uso das TD, tendo em vista que elas estão presentes no contexto sociocultural e econômico da atualidade.

Entretanto, o ensino por competência é regido pela Base Nacional Comum Curricular (BNCC), que elenca dez competências a serem desenvolvidas no decorrer da educação básica. Para tanto, elas definem condições para desenvolver capacidades para "mobilização de conhecimentos (conceitos e procedimentos), habilidades (práticas, cognitivas e socioemocionais), atitudes como valores para resolver demandas complexas da vida cotidiana, do pleno exercício da cidadania e do mundo do trabalho" (BRASIL, 2017, p. 8). Dentre essas competências básicas elencadas na BNCC, a de número 5 (cinco) discorre sobre o uso das TD, explicitando que o aluno, ao final da 
etapa básica de Ensino, deverá "compreender, utilizar e criar tecnologias digitais de informação e comunicação, de forma crítica, significativa, reflexiva e ética" (BRASIL, 2017, p. 9).

Assim, a formação do educando para o domínio das tecnologias não se restringe ao seu uso mecanizado, mas engloba as habilidades de compreensão, criação e análise do conteúdo e das ações. Além disso, há referência aos valores éticos que devem ser desenvolvidos tanto na comunicação quanto nas relações sociais proporcionadas pela internet.

Diante do exposto, não é suficiente somente inserir as tecnologias no ambiente escolar. Fazse necessário um olhar crítico do professor quanto ao uso das ferramentas digitais e da integração destas ao currículo. Sendo assim, elas podem proporcionar condições para realizar um planejamento docente em que a inclusão das TD esteja voltada para o desenvolvimento desses conhecimentos, habilidades e atitudes por parte dos educandos. A seguir, apresenta-se como pode ser desenvolvida a autoria e a M-Learning através do uso de um objeto de aprendizagem.

\subsection{Objeto de Aprendizagem: desenvolvimento da autoria e da M-learning}

Cada vez mais os recursos tecnológicos estão sendo utilizados no âmbito escolar e, com isso, faz-se necessário repensar novos modelos de materiais educacionais digitais com potencial para apresentar conteúdos e atividades de uma forma mais interativa, inovadora com o uso dos DM, por exemplo.

Muitos desses materiais são disponibilizados em forma de objetos de aprendizagem ou como uma unidade de ensino que pode ser reutilizada e adaptada conforme o contexto, público-alvo e modalidade de ensino. De acordo com Behar (2009, p.67), entende-se por objeto de aprendizagem "qualquer material digital, como, por exemplo, textos, animações, vídeos, imagens, aplicações, páginas web de forma isolada ou em combinação, com fins educacionais". Já Sonego et al. (2017) destacam que um OA pode ser considerado um material digital produzido com fins educacionais e com embasamento pedagógico. Neste sentido, o mesmo autor enfatiza a importância de que o professor tenha domínio dos conteúdos que serão abordados nesse $O A$, bem como das fases de aprendizagem de seus alunos, a fim de obter os melhores resultados e alcançar os objetivos propostos em seu planejamento (SONEGO et al., 2017). Dessa forma, a criação de OA permite que os conteúdos a serem trabalhados em aula sejam adequados aos propósitos do educando e/ou do professor, atendendo as necessidades do planejamento docente.

Assim, no contexto pedagógico, o uso dos objetos educacionais pode ser uma opção para que se desenvolva a aprendizagem móvel mediada pelo uso dos dispositivos. Segundo Melo e Carvalho (2014), a aprendizagem móvel pode expandir as possibilidades de aprendizagem, uma vez que propicia flexibilidade de tempo e espaço, visto não estar limitada à sala de aula. Desse modo, percebe-se que, através do uso dos DM, aumentam as possibilidades de planejamento e aplicabilidade desses recursos, devido a sua capacidade de permitir a mobilidade e acesso à internet, com maior praticidade, devido à facilidade de serem transportados pelos usuários (SONEGO; BEHAR, 2015).

Com base nos estudos da UNESCO (2014), sabe-se que cada vez mais pessoas estão tendo acesso a esses dispositivos e muitos países possuem planos para implementá-los nas escolas, 
como mediadores do processo de ensino e aprendizagem. No entanto, apesar das TD poderem fomentar a criatividade e tornar o educando sujeito de suas aprendizagens, a utilização delas por si só não garante melhorias no processo de ensino e aprendizagem. Faz-se necessário inseri-las em um contexto escolar inovador, em que o seu uso fique atrelado a uma concepção pedagógica de ensino que vise à autonomia, à criação, à autoria e ao protagonismo do aluno (MORAN, 2012).

Diante desse contexto, Demo (2018) ressalta que a escola tem o compromisso de garantir ao aluno o direito de aprender e isso não se dá com as práticas pedagógicas tradicionais. Dessa forma, o professor deve proporcionar atividades de ensino que permitam ao aluno desenvolver a sua autoria e emancipação. Demo (2018) atrela a aprendizagem à autoria, salientando que o papel da escola é criar espaços que possibilitem a desconstrução e reconstrução de conteúdo, possibilitando ao aluno o protagonismo na construção de seu conhecimento. Neste caso, o uso das tecnologias, especialmente dos DM, viabiliza múltiplas formas de aprendizagens, disponibilizando conteúdos e ferramentas para a criação de novos materiais. Entretanto, a escola precisa orientar o educando quanto ao uso dos DM para incentivar a autoria, tanto individual quanto coletiva, evitando a mera reprodução do material acessado (DEMO, 2009, 2015).

Ao referir-se à autoria, Demo $(2017$, p. 7) afirma que ela se forma "na habilidade de lidar com a realidade como ente interpretativo, formulador, analista, programador." Assim sendo, o docente pode propiciar experiências que favoreçam a leitura e análise crítica do meio em que o educando está inserido. Essa prática possibilitará ao estudante associar os conteúdos de aula com sua realidade, dando-Ihe os aportes para a reconstrução autoral desses conhecimentos. Já Papert (2005) também faz um alerta sobre o uso das tecnologias, salientando que mudanças podem ser significativas na educação. Mas, para isso, é necessário que os professores adquiram novas habilidades e novos conceitos e que a escola evolua. Reforçando essa linha de pensamento, Demo (2009, p. 67) afirma: "o professor precisa reestruturar-se num novo momento pedagógico e tecnológico, para atuar nele como sujeito, não como objeto". Assim, para que o professor oriente seus alunos na pesquisa e autoria, ele mesmo precisa tornar-se um pesquisador e autor.

Além da necessária reflexão sobre as práticas docentes, os autores Valente e Moran (2011, p. 99) salientam que "existem outros obstáculos que a escola precisa transpor para inserir as tecnologias". Segundo os autores, é preciso saber diferenciar informação de conhecimento; compreender o papel das tecnologias digitais na construção do conhecimento e ter uma visão administrativa e pedagógica que favoreça a construção de um projeto que viabilize o uso das TD como ferramentas educacionais. A capacidade de contornar esses obstáculos favorecerá um ensino voltado para a promoção do desenvolvimento das competências necessárias que possibilitarão aos jovens egressos do ensino médio atuarem de maneira ativa e crítica na sociedade a partir do uso dos DM.

Contudo, é inquestionável o fato de que as ferramentas tecnológicas, como os DM, representam um dos mais eficientes recursos para busca e o acesso à informação. Quanto aos benefícios do uso da internet no ambiente escolar, Moran; Masetto e Behrens (2013) sublinham que o aluno tem suas conexões linguísticas aumentadas, visto interagir com inúmeros textos e imagens. Esses autores ainda elencam atividades como criação de vídeos e áudios, páginas na 
internet, blogs e trabalho de forma colaborativa, dentro e fora do ambiente escolar, que possibilitam a construção de aprendizagens verdadeiramente significativas. Dessa maneira, pode-se desenvolver a aprendizagem móvel, permitindo aos alunos intensificarem o processo de aprendizagem independente de tempos ou espaços, ou seja, podem acessar o conteúdo de aula em qualquer lugar e a qualquer hora, por meio de um smartphone e tablet com acesso à internet (SONEGO; BEHAR, 2015).

Esse tipo de aprendizagem, também conhecida como M-Learning, está sendo cada vez mais utilizada devido ao fato do número crescente de estudantes com acesso aos DM e pelas diversas possibilidades que eles oferecem para a educação, com auxílio de um planejamento e acompanhamento docente. Conforme Sonego e Behar (2015), através dos DM, pode-se criar situações que oportunizam a aprendizagem, a comunicação e interação entre alunos e professor. Além disso, é possível oferecer condições para propor atividades variadas com o uso de OA, potencializando a aprendizagem dos alunos, explorando o desenvolvimento e o aprimoramento das competências tecnológicas. Desse modo, percebe-se a relevância em apresentar outros estudos sobre a utilização de objetos de aprendizagem e o uso dos DM nas escolas, especialmente, no ensino médio. Para tanto, a seguir, são elencados alguns trabalhos que corroboram para fundamentar o presente artigo.

\subsection{Trabalhos correlatos}

Em face às novas possibilidades na educação, oriundas da evolução cientifica e digital, as pesquisas acadêmicas sobre o uso educacional dos dispositivos móveis e sobre objetos de aprendizagem multiplicaram-se. Desse modo, considera-se pertinente recorrer a publicações que justificam e contribuem com o presente estudo. Para tanto, efetuou-se uma busca nas seguintes bases de dados: Google Acadêmico ${ }^{1}$ e Lume Repositório da UFRGS ${ }^{2}$. Essa varredura permitiu embasar e verificar a relevância do presente estudo. Neste sentido, utilizou-se a pesquisa das palavras-chave: "objeto de aprendizagem"; "ensino médio" e "educação básica".

Após a investigação por esses termos, foi registrado um total de 446 publicações on-line, entre monografias, dissertações e artigos científicos, no período de 2015 a 2020, nos idiomas português, inglês e espanhol. Estes foram os que se destacaram por apresentarem maior afinidade com a proposta deste artigo, excluindo-se as demais publicações que se referiam a outros níveis de ensino e/ou a formação docente. Assim, o quadro 1 (um) apresenta seis trabalhos, elegidos, em que foram considerados os seguintes critérios de busca e seleção:

a) conter a expressão exata no título ou no resumo: "objetos de aprendizagem";

b) apresentar perspectiva educacional voltada para educação básica, ou ensino médio;

c) conter as palavras-chave secundárias ao longo da obra como, por exemplo: escola, uso de dispositivos móveis ou smartphones.

Quadro 1 - Trabalhos on-line relacionados a objetos de aprendizagem e m-learning

\footnotetext{
${ }^{1}$ https://scholar.google.com.br/?hl=pt

2 https://lume.ufrgs.br/
} 


\begin{tabular}{|c|c|c|}
\hline ANO & PUBLICAÇÃO & RESUMO \\
\hline \multicolumn{3}{|c|}{ Google Acadêmico } \\
\hline 2015 & $\begin{array}{l}\text { BONOTTO, Aline Kempa; BISOGNIN, Eleni. } \\
\text { Contribuições de um Objeto de } \\
\text { Aprendizagem e dos Registros de } \\
\text { Representações Semióticas no Estudo da } \\
\text { Função Exponencial. Revista Novas } \\
\text { Tecnologias na Educação, v. } 13 \text { No 2, dez. } \\
\text { 2015. Porto Alegre: CINTED/UFRGS, } 2015 . \\
\text { Disponível em: } \\
\underline{\text { https://www.seer.ufrgs.br/renote/article/vie }} \\
\underline{\text { w/61443/36330 }}\end{array}$ & $\begin{array}{l}\text { O artigo analisa as contribuições de um AO. } \\
\text { Este foi elaborado para o conteúdo da função } \\
\text { exponencial, destinado a estudantes do ensino } \\
\text { médio. As autoras constataram que o uso do } \\
\text { OA foi significativo. Sendo capaz de despertar } \\
\text { a curiosidade, o interesse e participação dos } \\
\text { estudantes em aula e em relação ao referido } \\
\text { conteúdo. }\end{array}$ \\
\hline 2015 & $\begin{array}{l}\text { FERREIRA, Vinícius Hartmann; PETRÓ, } \\
\text { Vanessa; EICH, Luís Guilherme. Um Objeto } \\
\text { de Aprendizagem para a Disciplina de } \\
\text { Sociologia no Ensino Médio. Revista Novas } \\
\text { Tecnologias na Educação, v. } 13 \text { No 1, jul., } \\
\text { 2015. Porto Alegre: CINTED/UFRGS, 2015. } \\
\text { Disponível em: } \\
\underline{\text { https://www.seer.ufrgs.br/renote/article/vie }} \\
\underline{\text { w/57598 }}\end{array}$ & $\begin{array}{l}\text { O estudo apresenta um OA para auxiliar os } \\
\text { alunos na compreensão da linha do tempo } \\
\text { referente aos pensadores clássicos da } \\
\text { sociologia. Desse modo, apresenta suas } \\
\text { contribuições no decorrer da história de forma } \\
\text { cronológica. Os autores apontam que o OA } \\
\text { facilitou a compreensão do conteúdo, } \\
\text { apresentando-o de forma interativa, e auxiliou } \\
\text { os educandos na organização do pensamento } \\
\text { abstrato. }\end{array}$ \\
\hline 2015 & $\begin{array}{l}\text { SOUSA, José Mauro; MALHEIROS, Ana Paula } \\
\text { dos Santos; FIGUEIREDO, Newton. } \\
\text { Desenvolvendo práticas investigativas no } \\
\text { Ensino Médio: o uso de um Objeto de } \\
\text { Aprendizagem no estudo da Força de } \\
\text { Lorentz. Caderno Brasileiro de Ensino de } \\
\text { Física, v. 32, n. 3, p. 988-1006, dez. } 2015 \text {. } \\
\text { Disponível em: } \\
\underline{\text { https://periodicos.ufsc.br/index.php/fisica/a }} \\
\underline{\text { rticle/view/2175- }} \\
\text { p941.2015v32n3p988/30785 }\end{array}$ & $\begin{array}{l}\text { O artigo versa sobre a investigação das } \\
\text { possíveis contribuições do OA "Movimentos de } \\
\text { Cargas num Campo Magnético" para abordar } \\
\text { os conceitos de Eletromagnetismo. Como } \\
\text { resultado aponta que os estudantes } \\
\text { consideraram que o OA ajudou na } \\
\text { compreensão do conteúdo, instigando a } \\
\text { participação e envolvimento dos alunos } \\
\text { durante as aulas. }\end{array}$ \\
\hline 2016 & $\begin{array}{l}\text { CAPPELIN, Alcione; KALINKE, Marco Aurélio; } \\
\text { ARAÚjO, Angelita Minetto. O ensino de } \\
\text { funções na lousa digital a partir do uso de } \\
\text { um objeto de aprendizagem construído com } \\
\text { vídeos. XII Encontro Nacional de Educação } \\
\text { Matemática. Educação Matemática na } \\
\text { Contemporaneidade: desafios e } \\
\text { possibilidades São Paulo - SP, } 13 \text { a } 16 \text { de } \\
\text { julho de } 2016 \text { Comunicação Científica. Doc. } \\
\text { On-line. Disponível em: } \\
\text { http://www.sbem.com.br/enem2016/anais/ } \\
\text { pdf/6103 2656 ID.pdf }\end{array}$ & $\begin{array}{l}\text { Esse trabalho versa sobre a construção de um } \\
\text { OA com a utilização dos softwares Geogebra, } \\
\text { Hot Potatos e LibreOffice Impress. O objetivo } \\
\text { do OA priorizava o ensino de funções de } 10 \text { e } \\
2^{\circ} \text { graus com o uso da lousa digital. Portanto, } \\
\text { os autores concluíram que o uso do material } \\
\text { digital possibilitou o ensino de três formas: } \\
\text { visual, auditiva e tátil. Desse modo, } \\
\text { intensificou a aprendizagem dos alunos, } \\
\text { contribuindo com a interação, colaboração e a } \\
\text { construção do pensamento coletivo. Por fim, } \\
\text { destaca-se que auxiliou os pesquisadores na } \\
\text { compreensão das dificuldades dos alunos em } \\
\text { relação ao referido conteúdo. }\end{array}$ \\
\hline \multicolumn{3}{|c|}{ LUME/UFRGS } \\
\hline 2018 & $\begin{array}{l}\text { GODOI, Alessandro. O uso do aplicativo } \\
\text { WhatsApp na aprendizagem da língua } \\
\text { portuguesa. Disponível em: } \\
\text { https://lume.ufrgs.br/bitstream/handle/101 } \\
83 / 199435 / 001101391 . \text { pdf?sequence=1\&is } \\
\text { Allowed=y }\end{array}$ & $\begin{array}{l}\text { Este estudo analisou as contribuições do uso } \\
\text { dos smartphones, quanto a utilização do App } \\
\text { WhatsApp para o ensino e aprendizagem da } \\
\text { língua portuguesa. Para tanto, o professor } \\
\text { pesquisador criou um grupo de WhatsApp com } \\
\text { os participantes e utilizou esse recurso para } \\
\text { disponibilizar sites e informações sobre o }\end{array}$ \\
\hline
\end{tabular}




\begin{tabular}{|c|c|c|}
\hline & & $\begin{array}{l}\text { conteúdo a ser estudado. Assim, o App foi } \\
\text { utilizado para comunicação, interação, fonte de } \\
\text { pesquisa e realização de atividades interativas } \\
\text { e lúdicas. Nesse sentido, a conclui-se que } \\
\text { houve uma participação dos discentes mais } \\
\text { ativa nas aulas, comparando com as aulas sem } \\
\text { o uso do dispositivo. Sendo assim, considera- } \\
\text { se que o uso desse aplicativo pode gerar uma } \\
\text { contribuição educacional, promovendo a } \\
\text { utilização eficiente e responsável dos } \\
\text { smartphones. }\end{array}$ \\
\hline 2019 & $\begin{array}{l}\text { CLOSS, Ana Carina V. M-learning: o uso de } \\
\text { smartphones para o ensino e aprendizagem } \\
\text { de química. Disponível em: } \\
\text { https://www.lume.ufrgs.br/bitstream/handl } \\
\text { e/10183/197142/001097432.pdf?sequence } \\
\text { =1\&isAllowed=y }\end{array}$ & $\begin{array}{l}\text { Este estudo avaliou como os alunos do } 20 \text { ano } \\
\text { do ensino médio utilizaram os smartphones, } \\
\text { para o uso específico do App Khan Academy. } \\
\text { Este apresenta conteúdo referente as } \\
\text { equações químicas. Como resultado foi } \\
\text { apontado que a maioria dos estudantes } \\
\text { apresentaram um aproveitamento acima da } \\
\text { média esperada, explorando o uso do App e } \\
\text { concretizando novas formas de ensino e } \\
\text { aprendizagem sobre o referido conteúdo. }\end{array}$ \\
\hline
\end{tabular}

Fonte: As autoras (2020).

A partir das obras apresentadas no Quadro 1 (um), pode-se verificar que os autores convergem quanto às possibilidades educacionais do uso de objetos de aprendizagem na educação básica. Conforme visto, existe uma diversidade de OA, incluindo jogos, podcast e aplicativos. De acordo com os autores citados nos trabalhos destacados, percebe-se a gama de possibilidades que os OA podem apresentar para o âmbito educacional, especialmente, no ensino médio.

Neste sentido, os autores Bonotto e Bisognin (2015) e Sousa; Malheiros e Figueiredo (2015) enfatizam que a utilização de OA pode motivar os estudantes, promovendo novas formas de interação, comunicação, leitura, pesquisa, escrita e autoria nas aulas. Já Closs (2019) aponta que existem vantagens em relação ao uso de App para a aprendizagem. Essa situação pode estar relacionada ao fato de os estudantes já estarem familiarizados ao uso dos DM e, consequentemente, aproveitarem suas funcionalidades para promover novas oportunidades no processo de ensino e aprendizagem. Entretanto, autores como Cappelin e Kalinke (2016) destacam que a utilização de materiais digitais favorece não apenas o desenvolvimento cognitivo, mas também a compreensão docente sobre as dificuldades apresentadas pelos alunos durante a aula.

Embora as pesquisas aqui selecionadas enalteçam as contribuições educacionais dos OA, elas pouco contemplam as potencialidades de criação e autoria dos educandos. No entanto, convergem com os autores Demo (2018) e Moran (2012), que ressaltam a importância de proporcionar experiências educativas que favoreçam a interação, a autonomia e protagonismo discente. Neste caso, essas experiências são mediadas pelo uso dos DM e OA/App na prática escolar. Sendo assim, na próxima seção, apresenta-se a metodologia de estudo de caso utilizada nesta investigação.

\section{Metodologia}


Adotou-se a metodologia do tipo estudo de caso. De acordo com Yin (2005), é uma forma de pesquisa que se refere a fenômenos, fatos, acontecimentos contemporâneos que fazem parte do nosso cotidiano. Para tanto, Yin (2005) menciona que o diferencial desta em relação a outras pesquisas está relacionado à capacidade de poder fazer uso de diversos métodos para coletar dados, como a utilização de documentos, artefatos, entrevistas, observações e questionários. Desse modo, consegue-se aumentar a diversidade de instrumentos para reunir informações e ampliar as possibilidades de análise e discussão dos resultados. Neste sentido, a abordagem desta investigação é caracterizada por ser uma pesquisa qualitativa, visto não se ater a dados numéricos, mas com o entendimento da realidade sob a perspectiva do grupo social e suas características com seus significados, valores, crenças e atitudes (MINAYO, 2002).

Vinte estudantes do segundo ano do ensino médio participaram desta investigação, no período compreendido pelos meses de setembro e outubro de 2018. Como instrumento de coleta de dados, optou-se pelo uso de um questionário com esses alunos e uma ficha de autoavaliação para eles. Segundo Minayo (2002), esse método possibilita encontrar respostas às questões formuladas e confirmar, ou não, as hipóteses previamente concebidas.

Para análise dos dados, considerou-se o conteúdo do discurso, ou seja, as apreciações dos estudantes envolvidos na investigação, a partir de suas experiências e reflexões sobre o uso do GAF.Educação. De acordo com Minayo (2002), através da análise de conteúdo, pode-se encontrar respostas às questões formuladas e confirmar, ou não, as hipóteses previamente concebidas. Sob a perspectiva interpretativa, recorreu-se à contextualização com o objetivo de relacionar os fatos estudados com o meio social e cultural no qual os atores estão inseridos. Para tanto, a seguir, será demonstrada a descrição das etapas desta investigação.

\subsection{Detalhamento da Pesquisa}

Nessa etapa, foram traçadas estratégias para a construção do OA GAF.Educação. Para tanto, a elaboração do OA envolveu quatro etapas que estão embasadas de acordo com Amante e Morgado (2001): a) concepção do projeto; b) referencial teórico e planejamento; c) implementação; e d) avaliação.

Segundo Amante e Morgado (2001), cada etapa pode ser descrita da seguinte forma:

\section{a) Concepção do Projeto}

Nessa fase, determina-se o conteúdo e a equipe de trabalho, a caracterização do público alvo, a elaboração dos objetivos, a definição do tipo de aplicação e a previsão do contexto de utilização do OA. Após essa primeira etapa, passa-se para o estudo do referencial teórico e o planejamento do objeto de aprendizagem.

b) Referencial teórico e planejamento

Nessa etapa, são organizados e selecionados os conteúdos, escolhidos os textos, vídeos e imagens que comporiam o OA. Também se determina a estrutura do objeto, a forma de navegação, o design da interface e, ao longo desse processo, pondera-se sobre possíveis melhorias a partir da ideia inicial. 
c) Implementação

Nessa fase, escolhe-se o site, no caso AppyPie ${ }^{3}$, para construção do OA como objeto de aprendizagem, e elaboram-se os primeiros protótipos do GAF. No decorrer dessa etapa, o design pedagógico e a navegação do OA são testados até chegar à versão final para avaliação, ou seja, o GAF.Educação.

d) Avaliação

Finalizada a etapa de implantação, O OA está pronto para ser disponibilizado aos alunos, seguindo o planejamento de aula e, através disso, dá-se a avaliação do Objeto. Portanto, na próxima seção, descreve-se sobre os resultados e análise de dados deste estudo.

\section{Análise e discussão dos dados}

Para análise e discussão dos dados que serão apresentados a seguir, faz-se necessário apresentar os resultados de cada etapa traçada na metodologia desta pesquisa.

\subsection{Concepção do Projeto}

Para esta etapa, foram realizadas reuniões de planejamento em conjunto envolvendo as docentes das disciplinas de Geografia, Arte e Filosofia (GAF). Nesses encontros. foram definidos o público-alvo, o conteúdo e o design que teria o App/OA. Além disso, foi elencado o objetivo do $\mathrm{OA}$, ou seja, o de servir como um instrumento de pesquisa e informação, além de propor atividades que permitissem o desenvolvimento da M-Learning. Também foi determinado o nome que seria atribuído ao objeto: GAF. Educação, em referência às disciplinas a serem contempladas com o projeto.

Quanto ao público-alvo, foram selecionados os alunos do segundo ano do ensino médio, turma $2^{\circ} \mathrm{B}$, totalizando 20 estudantes. $\mathrm{O}$ motivo de escolha dessa turma deu-se pelo fato de as autoras do $\mathrm{OA}$ serem ambas docentes dessa série, pertencente à rede estadual de Barão do Triunfo, Rio Grande do Sul (RS).

\subsection{Referencial teórico e planejamento}

Primeiramente, foi escolhido um tema que contemplasse conteúdos previstos no currículo escolar e que fosse comum às três disciplinas. A utilização de um tema gerador para o desenvolvimento do projeto está embasada em Freire $(2016 ; 2018)$, sendo que o autor salienta a importância de refletir e investigar a realidade, procurando o desenvolvimento de uma consciência crítica. Dessa forma, procurou-se investigar um país asiático, cuja cultura tivesse sido influenciada por algum filósofo. Além disso, que houvesse um aspecto artístico que possibilitasse a recriação por parte dos alunos, que se relacionasse com o Brasil, especialmente com a realidade local, e que pudesse ser desenvolvido em um curto período. 
Seguindo esses critérios de seleção, chegou-se ao Japão: situado na Ásia, influenciado pelo confucionismo e budismo, onde a arte do origami ganhou grande repercussão. Ademais, esse país está presente no cotidiano dos alunos através das marcas comercializadas no Brasil e no município, tais como: tratores Kubota, Yanmar; aparelhos Panasonic, Toshiba, Sony, TDK; motocicletas Honda e Yamaha; camionetas Toyota, dentre outras.

Uma vez estipulado o país, determinou-se o tema intitulado "Conhecendo o Japão e suas relações com o Brasil". Assim sendo, o OA contempla os conteúdos das três disciplinas, sendo que, em Arte, seria trabalhado a arte do origami; em Filosofia, o confucionismo e o budismo e, em Geografia, os aspectos físicos, econômicos, políticos e sociais desse país.

A partir dessa definição, foi elaborado o plano de aula em conjunto, em que se elencaram os objetivos e os procedimentos a serem adotados. Foram escolhidos os textos, vídeos e imagens a serem inseridos no aplicativo/OA, bem como elaboradas as atividades propostas aos alunos, disponibilizadas por meio de Webquest e Quiz. A seleção de conteúdo atendeu ao critério de favorecer subsídios aos alunos para traçarem um paralelo entre o Japão e o Brasil, analisando semelhanças e diferenças entre eles, quanto aos aspectos: culturais, políticos, econômicos e sociais.

Concluída a etapa de planejamento, passou-se à implementação do $O A$, descrito a seguir.

\section{3 Implementação}

Para a criação do aplicativo, foi escolhido o site AppyPie, cuja versão é gratuita e online. Para execução desta etapa, foi elaborado um Menu com sete submenus (apresentação, textos, fotos, vídeos, Webquest, Quiz e planejamento didático).

O Menu permite ao usuário navegar pelo OA, que é um App, acessando seu conteúdo, conforme apresenta a figura 1 (um). No primeiro submenu, o "Quem Somos", é apresentado a descrição e objetivo do aplicativo. O segundo submenu "Fotos" (Figura 2) permite acessar três itens contendo fotos da praça de Shiga, localizada em Porto Alegre/RS. A segunda aba contém fotos de pontos turísticos do Japão e a terceira aba permite visualizar fotos que expressam a cultura japonesa no Brasil, como o bairro da Liberdade, em São Paulo. 
Figura 1 - Menu do App (Tela Inicial)

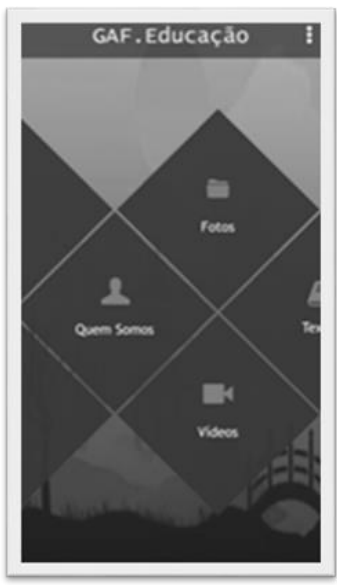

Fonte: GAF.Educação

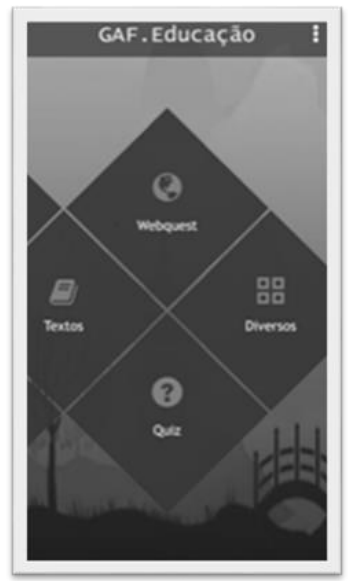

Figura 2 - Menu Foto

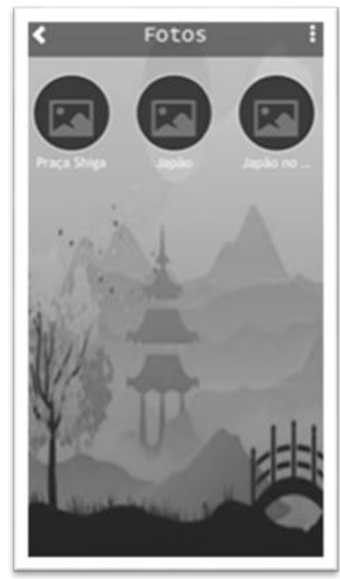

Fonte: GAF.Educação

O submenu ainda contém dois vídeos relacionados ao tema (Figura 3). O primeiro vídeo aborda a origem do origami. Já o segundo vídeo trata-se de um documentário sobre o Japão contendo informações da cultura e economia desse país. Já no submenu "Textos", foram disponibilizados cinco materiais: "Brasil e Japão: uma parceria econômica ao longo dos tempos"; "Japão na Copa do Mundo"; "Confúcio: o filósofo que mais inspirou o Japão"; "Budismo" e "Geografia do Japão", conforme apresenta a figura 4 (quatro). Além delas, pode ser encontrado, no ao, um submenu em que estão disponíveis uma Webquest, apresentando uma atividade que foi desenvolvida durante a implementação, e um Quiz - jogo com 10 questões sobre o Japão. 0 último submenu, contém o planejamento docente.

Figura 3 - Vídeos

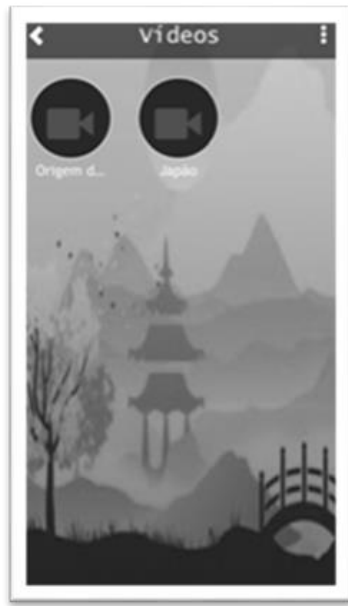

Fonte: GAF.Educação
Figura 4 - Textos

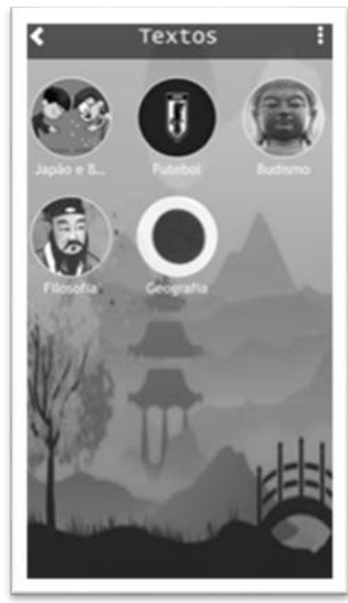

Fonte: GAF.Educação 
Como a atividade da Webquest envolveu a elaboração de vídeo, foi apresentado e compartilhado, no grupo de WhatsApp, o link do Google Drive, contendo um tutorial sobre como produzir, editar, salvar e compartilhar um vídeo através do smartphone 4 e sobre como utilizar o

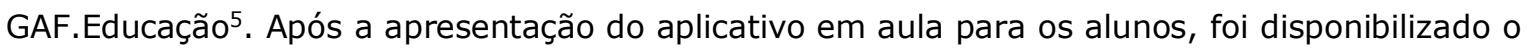
link para download e dada as instruções para realização dos estudos e tarefas extraclasse. Foram destinadas 10 horas/aula para a execução do planejamento de aula, sendo cinco horas presenciais e cinco horas para a realização da tarefa extraclasse explicitada na Webquest, presente no aplicativo.

\subsection{Avaliação}

A avaliação do aplicativo ocorreu através de discussões problematizadoras entre professoras e estudantes. Para tanto, apresentou-se o tema do projeto e a proposta pedagógica para o uso do OA GAF.Educação. Dessa forma, pretendeu-se salientar a relevância do estudo sobre o Japão e suas conexões com o Brasil/ RS/ Barão do Triunfo. Igualmente, buscou-se oferecer subsídios para que os alunos desenvolvessem a autoria, autonomia e protagonismo, uma vez que tinham disponível o OA como fonte de pesquisa e de instruções.

Dentre as atividades propostas, requereu-se dos alunos a produção de um vídeo onde fosse apresentado um aspecto do Japão, podendo ser relacionado a sua economia, política ou cultura, conforme a preferência do grupo. Por meio dessa atividade, permitiu-se verificar as habilidades e competência tecnológica desenvolvidas pelos educandos, bem como o centro de interesse deles. Através da produção textual, outra atividade de autoria, constataram-se os conhecimentos construídos durante a execução da proposta de trabalho.

Uma vez concluídas as atividades (produção textual e de vídeo, elaboração de origamis) propostas no planejamento docente, os alunos responderam uma ficha de autoavaliação. Dessa forma, pretendia-se indicar possíveis soluções para os obstáculos apontados, bem como analisar o processo de construção de competência tecnológica pelos alunos. Para tanto, destaca-se a seguir duas fichas de autoavaliação discente confome figuras 5 (cinco) e 6 (seis):

${ }^{4}$ https://drive.google.com/file/d/1uiNvksNb7uMDDR6UBsdqz1LwjXAaQ4cp/view

5 https://drive.google.com/file/d/1Ct9XN-eTdOs2p5Bp6JKHMw3P0927V1QI/view?usp=sharing 
Figura 5 - Ficha de autoavaliação

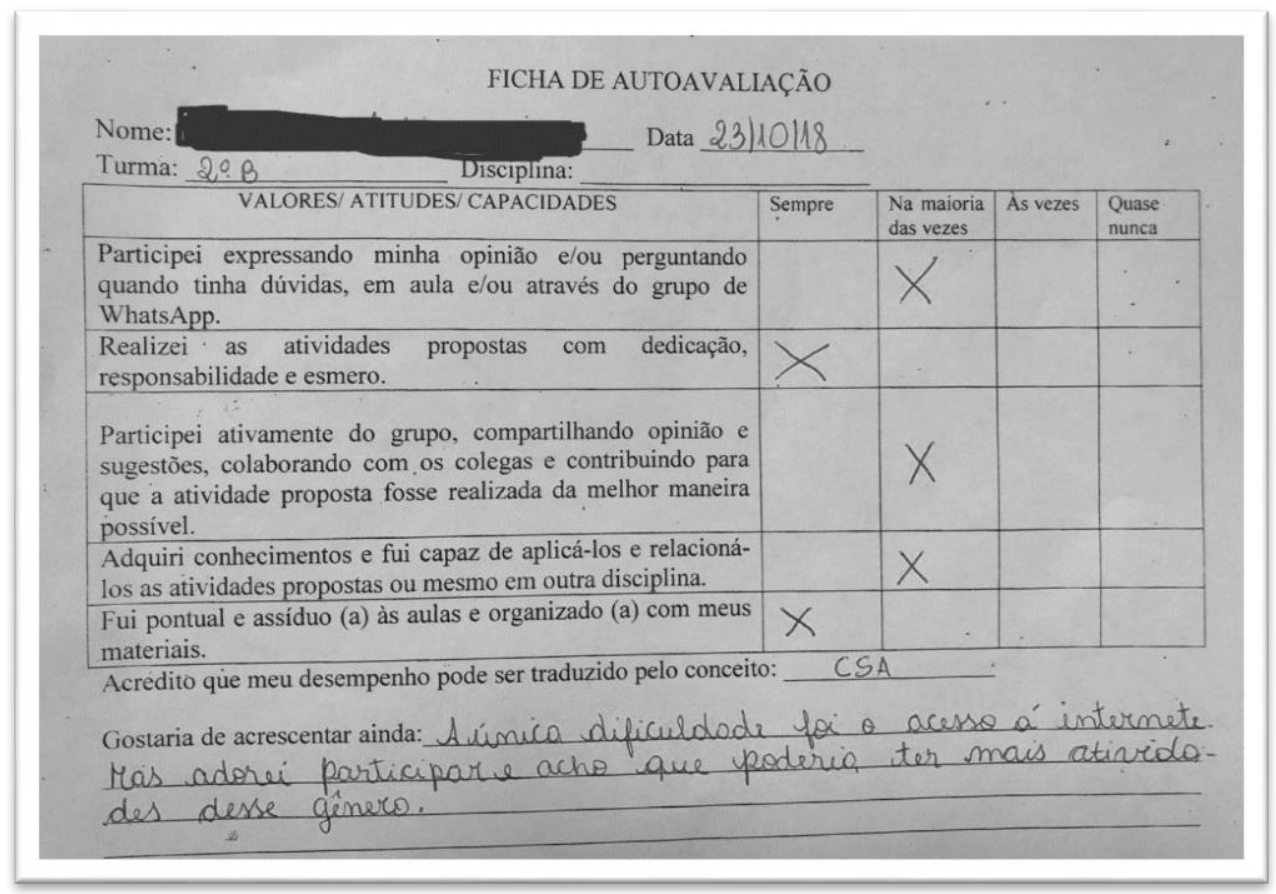

Fonte: Estudante G

Figura 6 - Ficha de autoavaliação 


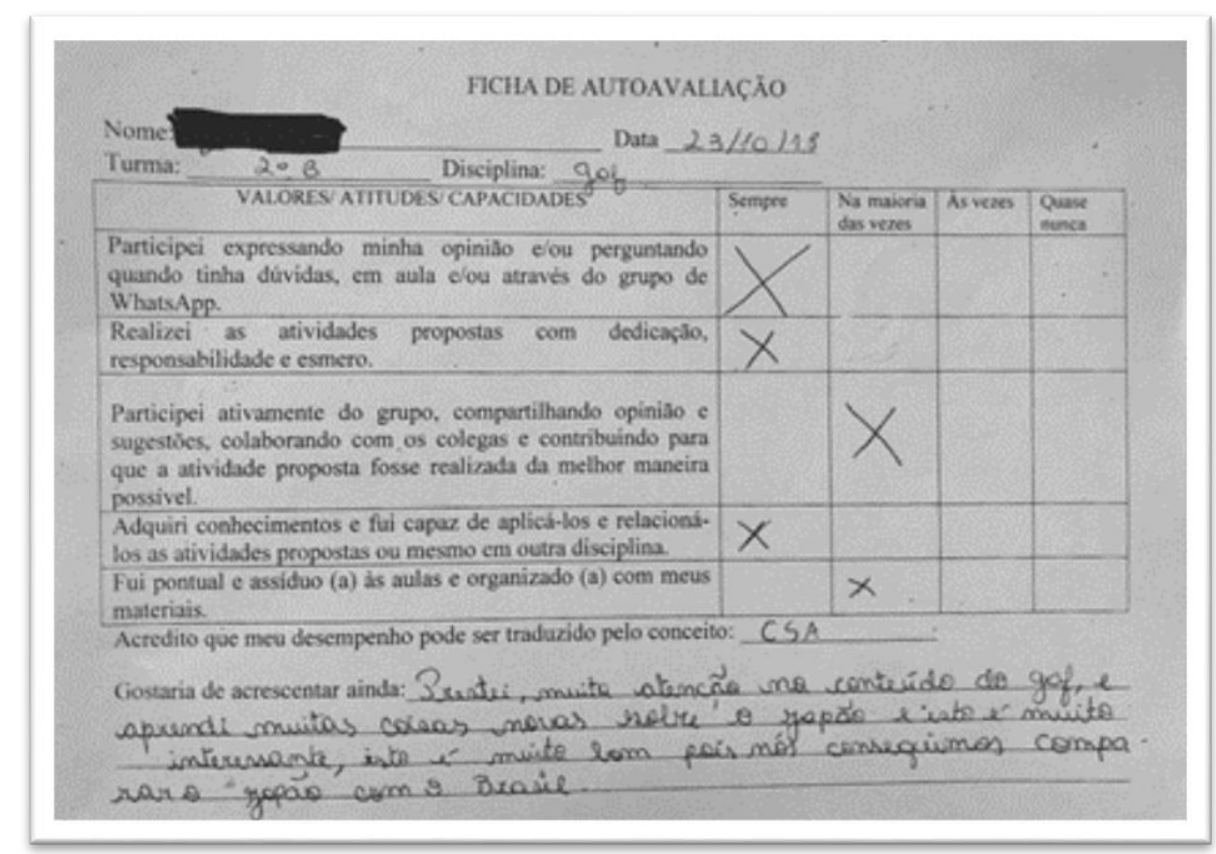

Fonte: Estudane $\mathrm{H}$

As autoavaliações contribuiram na ponderação e análise do processo de aprendizagem dos educandos. Como pode-se constatar nas fichas representadas nas figuras 5 (cinco) e 6 (seis), os alunos reconheceram a contribuição do OA partir dos conteúdos trabalhados em aula, do aproveitamento dos alunos quanto ao uso do aplicativo e o desenvolvimento da aprendizagem.

Em relação aos pontos positivos do OA GAF.Educação, sobressaíram-se algumas falas dos estudantes verificadas no questionário, em que explicitam que o aplicativo auxiliou-os na aprendizagem, fornecendo informação e otimizando o tempo de estudo, visto que porque os conteúdos a serem desenvolvidos em aula estavam disponíveis em um único lugar (no $O A$ ) e puderam ser acessados dentro e fora do ambiente escolar. Neste sentido, destacaram-se algumas contribuições discentes sobre os aspectos positivos, expressas no questionário aplicado após a utilização do referido OA:

"Informações disponíveis todas em um só lugar" (estudante a)

"O app nos forneceu informações e nos auxiliou a criar conteúdo" (estudante b)

"Foi muito importante para nos mostrar que é possível uma aprendizagem pedagógica com uso de celular, tiramos dúvidas e aprendemos muitas coisas!" (estudante c). 
A partir desses estratos, pode-se perceber que os educandos consideraram o objeto relevante por disponibilizar conteúdo a todo momento necessário, pois estava disponível junto aos DM. Também foi evidenciada a contribuição do App/OA para a autoria, de acordo com o estudante b. Neste sentido, percebeu-se que, antes dessa atividade, os estudantes utilizavam, na maioria das vezes, os smartphones para comunicação, não o fazendo para criar conteúdo com objetivos educacionais, isso se apresentou como uma inovação para os discentes. Além disso, conforme o estudante c, o uso do OA no DM permitiu outra percepção quanto ao smartphone, ou seja, seu potencial educacional, sendo que, antes, o aparelho tinha função para entretenimento, realizar e receber ligações, utilizar redes sociais, jogos e fazer pesquisas de seu interesse pessoal. Mais uma vez, os estudantes destacam que ficaram surpresos e satisfeitos em poder realizar atividades escolares através de um dispositivo móvel, ou seja, conheceram novas formas de potencializar o processo de ensino e aprendizagem dentro e fora da sala de aula.

Dentre as limitações do OA e os aspectos negativos, os alunos assinalaram as dificuldades encontradas em razão da baixa conectividade (estudante $\mathrm{g}$ ). A questão da conexão da internet é um fator que envolve todo município e, principlamante, os estudantes que residem na zona rural. Além disso, o período de realização das atividades com o OA foi de chuvas intensas na região, o que contribuiu negativamante para efetivação do sinal de telefone e internet, tanto wifi quanto rede móvel. Outro fator negativo é a questão do surgimento de muitos anúncios publicitários, que tornava cansativo o ato de acessar o App. Esse fator está condicionado ao fato de o recurso ser gratuito para o usuário, sendo os anúncios uma maneira de divulgar os patrocinadores. Entretanto, considera-se que eles não atrapalham a qualidade do conteúdo apresentado. Diante desse contexto, os estudantes mencionaram as seguintes situações:

"Se torna às vezes cansativo por conta das propagandas exibidas durante o manuseio" (estudante e)

"Apesar do conteúdo ser bom, creio que há muitos textos e poucas atividades diferentes para se realizar em aula, isso acaba deixando a aula mais monótona. Outro problema á as propagandas que aparecem com muita frequência" (estudante $f$ )

Os estudantes declararam uma necessidade, a questão de que o App pudesse ser acessado offline, isso só poderia acontecer se ele estivesse armazenado em uma loja de aplicativos, permitindo o seu download, o que não foi possível na versão gratuita utilizada através do site Appy Pie. Além disso, se fosse viável fazer o download, seria uma possibilidade para os discentes darem continuidade nas atividades até mesmo nos períodos em que estivessem sem conexão com a internet.

A partir das considerações dos estudantes, pode-se entender que o uso do OA favoreceu a Mlearning e a aquisição de conhecimentos nas disciplinas de Geografia, Arte e Filosofia. Também os auxiliou na realização das atividades propostas no planejamento de aula das professoras, tais como produção textual, de vídeo e elaboração de origamis. 


\section{Considerações finais}

O objetivo deste artigo foi analisar as potencialidades e desafios para utilização do GAF. EDUCAÇÃO, como um objeto de aprendizagem para o desenvolvimento da M-learning em sala de aula. Sendo assim, esse OA teve como propósito contribuir para ampliar as formas de aprendizagem, potencializando a autoria e o desenvolvimento da competência tecnológica com alunos do Ensino Médio. Entende-se que a utilização de OA com fins pedagógicos possibilitou maior autonomia e protagonismo por parte do educando em seu processo de aprendizagem. Isso ocorreu porque the forneceu meios para construir seu conhecimento através da variedade de conteúdo disponibilizado, proporcionando ao aluno gerenciar seu tempo para a realização das atividades extraclasse e buscar soluções aos possíveis problemas apresentados.

O OA GAF.Educação foi planejado e desenvolvido de forma interdiscipinar, visando abranger as disciplinas de Geografia, Filosofia e Arte. Por intermédio desse recurso digital, os educandos tiveram a possibilidade de utilizar os smartphones, atribuindo-lhes a função educacional, ainda pouco explorada no contexto escolar investigado. Durante sua implementação e avaliação, constatou-se que ele serviu como instrumento de pesquisa, informação e interação, auxiliando no desenvolvimento de competência tecnológica específica para esse fim. Ela também se sustentou em teóricos que ratificam a relevância da M-learning e da utilização de OA para fins educacionais. Contudo, acredita-se que a utilização do OA oportunizou novas formas de aprendizado, tornado-o mais atrativo e aproximando os educandos das tecnologias digitais por meio dos dispositivos móveis.

\section{Referências}

ANTUNES, M.T.R.B. GAF.Educação: um estudo sobre a construção e implantação de um aplicativo educacional. Trabalho de Conclusão de Curso, apresentado como requisito parcial para a obtenção do grau de Especialista em Mídias na Educação, pelo Centro Interdisciplinar de Novas Tecnologias na Educação da Universidade Federal do Rio Grande do Sul - CINTED/UFRGS, $2018 . \quad$ Disponível em: https://lume.ufrgs.br/handle/10183/201558.

. GAF.Educação: um estudo sobre a construção e uso de aplicativo educacional. In: Porto Alegre, nov. 2019. Anais do XXVII Ciclo de Palestras sobre Novas Tecnologias na Educação, p. 36-46. Disponível em: https://www.ufrgs.br/cinted/wp-content/uploads/2019/2019-Anais-ciclo.pdf?_t=1576172756.

AMANTE, L.; MORGADO, L. Metodologia de concepção e desenvolvimento de aplicações educativas: o caso dos materiais hipermídia. Disponível em: https://repositorioaberto.uab.pt/bitstream/10400.2/4348/1/L\%C3\%BAcia\%20Amante_Lina\%20Morgado.p df $>$. Acessado em 10 de out de 2018.

BEHAR, P.A. [Organizadora]. Competências em educação a distância. Porto Alegre: Penso, 2013.

BONOTTO, A.K.; BISOGNIN, E. Contribuições de um Objeto de Aprendizagem e dos Registros de Representações Semióticas no Estudo da Função Exponencial. Revista Novas Tecnologias na Educação, v. 13 No 2, dez. 2015. Porto Alegre: CINTED/UFRGS, 2015. Disponível em: https://www.seer.ufrgs.br/renote/article/view/61443/36330 
; et al. Modelos pedagógicos de educação a distância. Porto Alegre: Artmed, 2009.

BRASIL. Ministério da Educação. Base Nacional Comum Curricular. Brasília, 2017.

Lei no 9394/96 de 20 de dezembro de 1996. Lei de Diretrizes e Bases da Educação Nacional: que estabelece as diretrizes e bases da educação nacional. Brasília, Brasil: Senado Federal, 2017.

Ministério da Educação. Parâmetros Curriculares Nacionais do Ensino Médio. Brasília, 2000. Disponível em: http://portal.mec.gov.br/programa-saude-da-escola/195-secretarias-112877938/sebeducacao-basica-2007048997/12598-publicacoes-sp-265002211.

CAPPELIN, A.; KALINKE, M.A.; ARAÚJO, A.M. O ensino de funções na lousa digital a partir do uso de um objeto de aprendizagem construído com vídeos. XII Encontro Nacional de Educação Matemática. Educação Matemática na Contemporaneidade: desafios e possibilidades São Paulo - SP, 13 a 16 de julho de 2016 Comunicação Científica. Doc. On-line. Disponível em: http://www.sbem.com.br/enem2016/anais/pdf/6103_2656_ID.pdf

CLOSS, A.C.V. M-learning: o uso de smartphones para o ensino e aprendizagem de química. Disponível em: https://www.lume.ufrgs.br/bitstream/handle/10183/197142/001097432. pdf?sequence=1\&isAllowed=y

DEMO, P. Atividades de aprendizagem: sair da mania do ensino para comprometer-se com a aprendizagem do estudante [recurso eletrônico] / Pedro Demo. Campo Grande, MS: Secretaria de Estado de Educação do Mato Grosso do Sul - SED/MS, 2018. 180 p., 1,27 MB; ePDF

Aprendizagem e novas tecnologias. Revista Brasileira de Docência, Ensino e Pesquisa em Educação Física - ISSN 2175-8093 - Vol. 1, n. 1, p.53-75, agosto/2009. Disponível em: http://www.pucrs.br/ciencias/viali/doutorado/sat/textos/80-388-1-PB.pdf

. Autoria do aluno. Prof. Pedro Demo Blog. São Paulo, 31 de janeiro de 2018. Disponível em: < https://docs.google.com/document/d/e/2PACX-1vQ3Ztdnl_XZleXiSDen_DmLxpiBpoHrcREehRRkr15xbkkPcyrfrs]sS65Kcf7nXs4QV74VCgaNvUq/pub>.

Aprender como autor. São Paulo: Atlas, 2015.

FERREIRA, V.H.; PETRÓ, V.; EICH, L.G. Um Objeto de Aprendizagem para a Disciplina de Sociologia no Ensino Médio. Revista Novas Tecnologias na Educação, v. 13 No 1, jul., 2015. Porto Alegre: CINTED/UFRGS, 2015. Disponível em: https://www.seer.ufrgs.br/renote/article/view/57598

FREIRE, P. Educação e mudança. 38 ed. rev. e atual. Rio de Janeiro/São Paulo: Paz e Terra, 2018.

. Pedagogia da autonomia: saberes necessários à prática educativa. 54 ed. Rio de Janeiro: Paz e Terra, 2016.

GODOI, A. O uso do aplicativo WhatsApp na aprendizagem da língua portuguesa. Disponível em: https://lume.ufrgs.br/bitstream/handle/10183/199435/001101391.pdf?sequence=1\&isAllowed=y

MELCHIOR, M.C. Avaliação Pedagógica: função e necessidade. Porto Alegre: Editora Mercado Aberto, 1999.

MELO, R.S.; CARVALHO, M.J.S. Aplicativos educacionais livres para mobile learning. Revista Tecnologias na Educação, Ano 6, no 10, jul./2014. Disponível em: < http://tecedu.pro.br/wpcontent/uploads/2015/07/Art3-ano6-vol10-julho2014.pdf>. Acessado em: 10 de ago. de 2018.

MINAYO, M.C.S. [organizador]. DESLANDES, S.F.; NETO, O.C. [colaboradores]. Pesquisa social: teoria, método e criatividade. 21 ed. Rio de Janeiro (Brasil): Vozes, 2002.

MORAN, J.M. A educação que desejamos: novos desafios e como chegar lá. $5^{a}$ ed. Caminas, SP: Papirus, 2012.

MORAN, J.M.; MASETTO, M.T.; BEHRENS, M.A. Novas tecnologias e mediação pedagógica. 21 ed. rev. e atual. Campinas - SP: Papirus, 2013. 
PAPERT, S. ¿Cómo pensar sobre tecnología y aprendizaje? - Una llamadaal diálogo. Revista DIM: Didáctica, Innovación y Multimedia, Núm. 1, Junio 2005.

PERRENOUD, P. Desenvolver competências ou ensinar saberes? A escola que prepara para a vida. Tradução: Laura Solange Pereira. Porto Alegre, RS: Penso, 2013.

SONEGO, A.H.S.; BEHAR, P.A. M-Learning: Reflexões e Perspectivas com o uso de aplicativos educacionais. Nuevas Ideas en Informática Educativa TISE 2015, v. 11. Disponível em: <http://www.tise.cl/volumen11/TISE2015/521-526.pdf>. Acessado em: 25 de abr de 2018

SONEGO, A.H.S.; RIBEIRO, A.C.R.; MACHADO, L.R.; BEHAR, P.A. Objeto de Aprendizagem EDUMOBILE estratégias pedagógicas para o uso da m-learning em sala de aula: do planejamento à implementação. Anais do $16^{\circ}$ Ergodesign -Congresso Internacional de Ergonomia e Usabilidade de Interfaces Humano Tecnológica: Produto, Informações Ambientes Construídos e Transporte $16^{\circ}$ USIHC - Congresso Internacional de Ergonomia e Usabilidade de Interfaces Humano Computador CINAHPA | 2017 - Congresso Internacional de Ambientes Hipermídia para Aprendizagem.

SOUSA, J.M.; MALHEIROS, A.P.S.; FIGUEIREDO, N. Desenvolvendo práticas investigativas no Ensino Médio: o uso de um Objeto de Aprendizagem no estudo da Força de Lorentz. Caderno Brasileiro de Ensino de Física, v. 32, n. 3, p. 988-1006, dez. 2015. Disponível em:

https://periodicos.ufsc.br/index.php/fisica/article/view/2175-7941.2015v32n3p988/30785

UNESCO. Diretrizes de políticas para a aprendizagem móvel. Publicado pela Organização das Nações Unidas para a Educação, a Ciência e a Cultura, UNESCO, 2014, Paris, France. Tradução Rita Brossard. Disponível em:<http://www.unesco.org/new/pt/brasilia/about-this-office/single-view/news/diretrizes_

de_politicas_da_unesco_para_a_aprendizagem_movel_pdf_only/\#.VZ5EOvgju1E>. Acessado em: Set de 2018.

VALENTE, J.A. O computador na sociedade do conhecimento. Coleção Informática para mudança na educação. Ministério da Educação - Secretaria de Educação à Distância. Brasília, Brasil: Programa Nacional de Informática na Educação, 2005.

VALENTE, J.A.; MORAN, J.M. Educação a distância: pontos e contrapontos. São Paulo: Summus, 2011.

YIN, R.K. Estudo de Caso: planejamento e métodos. 3 ed. Porto Alegre, Brasil: Bookman Companhia Ed, 2005.

Recebido em abril de 2020.

Aprovado para publicação em julho de 2020.

Anna Helena Silveira Sonego

Pós-Graduação e Pós-Doutorado em Informática na Educação - PPGIE - Universidade Federal do Rio Grande do Sul - UFRGS, Brasil, sonego.anna@gmail.com

Maria Tanise Raphaelli Bosquerolli Antunes

Formación Avanzada en Educación da Faculdad de Ciencias de la Educación - Universidad de la Empresa, UDE, Montevideo; Maestía en Educación - E.E.E.M.José Joaquim de Andrade, RS - Brasil, taniseantunes@ yahoo.com.br 